\title{
Arterial occlusive disease of the lower extremities: Do women differ from men in occurrence of risk factors and response to invasive treatment?
}

\author{
Nancy L. Harthun, MD \\ Vasana Cheanvechai, $\mathrm{MD}^{\mathrm{b}}$ \\ Linda M. Graham, MD ${ }^{\mathrm{c}}$ \\ Julie A. Freischlag, MD ${ }^{d}$ \\ Vivian Gahtan, MD
}

See related editorials on pages 314,322 and 325 .
From the Division of TCV Surgery, ${ }^{a}$ University of Virginia Health System, Charlottesville, Va; the Division of Vascular Surgery, ${ }^{\mathrm{b}}$ University of Maryland, Baltimore, Md; the Department of Vascular Surgery, ${ }^{\mathrm{c}}$ the Cleveland Clinic Foundation, Cleveland, Ohio; the Department of Surgery, ${ }^{\mathrm{d}}$ Johns Hopkins School of Medicine, Baltimore, Md; and the Section of Vascular Surgery, ${ }^{\mathrm{e}}$ Yale University School of Medicine, New Haven, Conn.

This is a project of the Society of Vascular Surgery, Committee on Women's Issues.

Received for publication Sept 29, 2003; accepted for publication Oct 6, 2003.

Address for reprints: Vivian Gahtan, MD, SUNY Upstate Medical University College of Medicine, Department of Surgery, 750 East Adams St, Syracuse, NY 13210 (Email: gahtanv@upstate.edu).

J Thorac Cardiovasc Surg 2004;127:318-21 $0022-5223 / \$ 30.00$

Copyright () 2004 by The American Association for Thoracic Surgery

doi:10.1016/j.jtcvs.2003.10.020

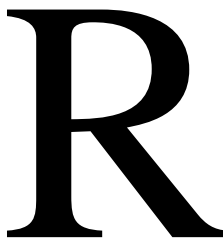

esults of lower extremity revascularization for peripheral arterial occlusive disease (PAD) are difficult to analyze because a multitude of factors might have a significant effect on outcome. These factors include the following: (1) the indication to intervene (claudication, rest pain, or tissue loss); (2) the location or locations of hemodynamically significant atherosclerotic plaque; (3) the number of associated arterial segments affected by disease; (4) the diameter of treated arterial segments; (5) the intervention performed; (6) the type and quality of the conduit if a bypass graft is performed; and (7) the ability of the patient and health care team to reduce risk factors (control diabetes, hyperlipidemia, and hypertension and reduce or stop cigarette smoking). For example, unilateral inflow disease might involve occlusion or stenosis of the common iliac artery, the external iliac artery (EIA), or both. Treatment options include axillofemoral, iliofemoral, or femoral-femoral bypass grafting; aortobifemoral bypass grafting; or percutaneous revascularization with angioplasty, stenting, or both. Each patient might have multiple important issues to consider, and therefore comparing patients while controlling for all these variables is a monumental task. Despite the obstacles, many investigators have attempted to control the wide array of variables to determine whether a significant difference in outcomes exists for men and women. For this article, both surgical infrainguinal revascularization and percutaneous and surgical treatment of aortoiliac occlusive disease are considered.

\section{Infrainguinal Arterial Bypass Grafting}

Most of the studies that examine infrainguinal surgical revascularization in women are retrospective analyses from a single institution. Unfortunately, this type of study has resulted in frequent comparisons of dissimilar patient groups (Table 1). ${ }^{1-6}$ Only 2 studies compared men and women who had no significant differences regarding age, smoking history, and incidence of diabetes. ${ }^{5,6}$ In the other reports, women were significantly older than men. ${ }^{1-4}$ The frequency of risk factors, especially smoking and diabetes mellitus, differed between women and men in most of these article. In 4 reports significantly more men smoked cigarettes. ${ }^{1-4}$ Diabetes mellitus was more common in men in one report ${ }^{2}$ and more common in women in another report, ${ }^{1}$ and 4 reports did not show a significant difference with respect to diabetes. ${ }^{3-6}$ Only one of these article reported the frequency of hyperlipidemia, and no difference was noted between men and women regarding this risk factor. ${ }^{6}$

Given the significant differences between the 2 groups being compared in all but 1 of these studies, it is not surprising that outcomes between men and women in these reports were frequently contradictory. Outcomes were measured in terms of 4 major end points (Table 2). 
TABLE 1. Demographic differences in men and women at the time of infrainguinal surgical revascularization

\begin{tabular}{|c|c|c|c|c|c|c|c|}
\hline \multirow[b]{2}{*}{ Reference } & \multirow{2}{*}{$\begin{array}{c}\text { No. of } \\
\text { infrainguinal } \\
\text { reconstructions }\end{array}$} & \multicolumn{2}{|c|}{ Diabetes mellitus } & \multicolumn{2}{|c|}{ Age (y) } & \multicolumn{2}{|c|}{ Cigarette smoking } \\
\hline & & Men & Women & Men & Women & Men & Women \\
\hline Roddy and colleagues ${ }^{1}$ & 5880 & $50 \%$ & $53 \% *$ & 66 & $71^{*}$ & $44 \%$ & $27 \% *$ \\
\hline Harris and colleagues ${ }^{2}$ & 823 & $59 \%$ & $48 \% *$ & 65 & $68^{*}$ & $84 \%$ & $66 \% *$ \\
\hline Belkin and colleagues ${ }^{3}$ & 582 & $38 \%$ & $42 \%$ & 67 & $71^{*}$ & $60 \%$ & $47 \% *$ \\
\hline Magnant and colleagues 4 & 381 & $47 \%$ & $52 \%$ & 69 & $72^{*}$ & $68 \%$ & $56 \% *$ \\
\hline Mays and colleagues 5 & 165 & $48 \%$ & $56 \%$ & 67 & 67 & $71 \%$ & $66 \%$ \\
\hline Frangos and colleagues ${ }^{6}$ & 217 & $56 \%$ & $58 \%$ & 67 & 69 & $65 \%$ & $52 \%$ \\
\hline
\end{tabular}

${ }^{*} P<.05$ comparing men with women.

TABLE 2. Outcome differences after infrainguinal revascularization in men and women

\begin{tabular}{|c|c|c|c|c|c|c|c|c|c|c|c|}
\hline \multirow[b]{2}{*}{ Reference } & $\begin{array}{r}\text { Peri } \\
\text { m }\end{array}$ & $\begin{array}{l}\text { rative } \\
\text { lity }\end{array}$ & $\begin{array}{l}\text { Per } \\
\text { com }\end{array}$ & $\begin{array}{l}\text { rative } \\
\text { nd } \\
\text { ations }\end{array}$ & $\begin{array}{c}\text { Length } \\
\text { of }\end{array}$ & \multicolumn{2}{|c|}{ Limb salvage } & \multicolumn{2}{|c|}{$\begin{array}{l}\text { Long-term } \\
\text { survival }\end{array}$} & \multicolumn{2}{|c|}{$\begin{array}{c}\text { Secondary graft } \\
\text { patency }\end{array}$} \\
\hline & $\mathbf{M}$ & $\mathbf{W}$ & $\mathbf{M}$ & $\mathbf{w}$ & follow-up, y & M & $\mathbf{w}$ & M & $\mathbf{W}$ & $\mathbf{M}$ & $\mathbf{w}$ \\
\hline Roddy and colleagues ${ }^{1}$ & $3 \%$ & $4 \%$ & $3 \%$ & $4 \% *$ & 10 & $88 \%$ & $93 \%$ & $39 \%$ & $34 \%$ & $55 \%$ & $58 \%$ \\
\hline Harris and colleagues ${ }^{2}$ & $4 \%$ & $3 \%$ & NR & NR & 5 & $91 \%$ & $96 \%$ & $44 \%$ & $44 \%$ & $71 \% \dagger$ & $67 \% \dagger$ \\
\hline Belkin and colleagues ${ }^{3}$ & $3 \%$ & $1 \% *$ & $3 \%$ & $14 \% *$ & 10 & $92 \%$ & $88 \%$ & $24 \%$ & $36 \%$ & $77 \%$ & $74 \%$ \\
\hline Magnant and colleagues 4 & $2 \%$ & $4 \%$ & NR & NR & 3 & $89 \%$ & $82 \%$ & $72 \%$ & $54 \% *$ & $86 \%$ & $69 \% *$ \\
\hline Mays and colleagues ${ }^{5}$ & $2 \%$ & $5 \%$ & NR & NR & $3 / 5 \ddagger$ & $93 \%$ & $87 \%$ & $58 \%$ & $42 \% *$ & $98 \%$ & $97 \%$ \\
\hline Frangos and colleagues 6 & $1 \%$ & $5 \%$ & $9 \%$ & $21 \% *$ & 5 & $81 \%$ & $87 \%$ & $71 \%$ & $75 \%$ & $87 \%$ & $82 \%$ \\
\hline
\end{tabular}

$M$, Men; $W$, women; $N R$, not reported.

${ }^{*} P<.05$ between men and women from the same study.

tPrimary patency.

¥Length of limb salvage and graft patency, 3 years; length of survival follow-up, 5 years.

\section{Limb Salvage}

One study demonstrated statistically significant higher limb salvage in women 10 years after surgical intervention, ${ }^{1}$ but no significant difference was reported in terms of limb salvage in 4 other studies that reported this outcome..$^{2-4,6}$

\section{Perioperative Complications and Mortality}

All series that reported morbidity identified a significantly higher wound complication rate for women. ${ }^{1,3,6}$ One study, which examined perioperative myocardial infarction, reported a higher rate of this complication in women. ${ }^{5}$ Perioperative mortality did not differ between men and women in most studies ${ }^{1,2,4-6}$; however, one study did demonstrate higher perioperative mortality in men. ${ }^{3}$

\section{Graft Patency}

Overall long-term graft patency did differ in one study, which identified worse outcomes for women: primary patency at 1 and 3 years for women was 59\% and 54\%, respectively, versus $73 \%$ and $70 \%$ for men, and secondary patency at 1 and 3 years for women was $75 \%$ and $69 \%$, respectively, versus $89 \%$ and $86 \%$ for men. ${ }^{4}$ Belkin and colleagues $^{3}$ identified a statistically significant difference only when a subset of grafts (those to the tibial vessels) were evaluated. Secondary patency in these grafts at 5 years was $70 \%$ for women and $81 \%$ for men. ${ }^{3}$ The overall graft patency in this study was not different for men and women: primary and secondary patency for women and men were $68 \%$ and $74 \%$ and $58 \%$ and $77 \%$, respectively. No significant differences in primary, primary-assisted, and secondary graft patency between women and men were reported in 4 studies. ${ }^{1,2,5,6}$

\section{Long-term Survival}

Decreased long-term survival was reported in patients with diabetes (both men and women) in one study. ${ }^{1}$ Two studies identified poor long-term survival in women, and this difference was statistically significant and especially notable for women with diabetes. ${ }^{4,5}$ Four studies demonstrated no difference between men and women regarding long-term survival. ${ }^{1-3,6}$

What does all this information mean? In the studies reviewed, limb-salvage rates did not differ between men and women. Limb salvage is an important end point because it is the goal of pursuing treatment of PAD. Similarly, overall secondary patency rates differed in only one study. ${ }^{4}$ This study enrolled women significantly older than the men 
enrolled in the study at the time of the operation, and the women experienced significantly reduced long-term survival when compared with the men. These differences might contribute to the reduced secondary patencies noted in women in this study. Roddy and associates ${ }^{1}$ reported the largest cohort in this group of studies. Five thousand eight hundred and eighty infrainguinal reconstructions were reviewed in their analysis. No difference was noted in graft patency between men and women. In addition, the 2 studies that enrolled men and women with similar demographic data also reported no significant differences in graft patency. ${ }^{5,6}$ Consequently, these studies suggest that probably no significant difference in long-term patency of infrainguinal grafts exists between men and women.

A difference in wound complications between men and women who undergo infrainguinal surgical revascularization has been a relatively consistent finding. In addition to the studies mentioned previously, Nam and coworkers ${ }^{7}$ specifically examined the issue of wound complications and identified female sex as an independent risk factor for incisional complications after infrainguinal vein bypass grafting. The reasons for this difference are unclear. Perhaps some metabolic difference exists that predisposes women to increased wound complications. It also is possible that women have higher fat content in their soft tissue prone to ischemia and subsequent poor healing. Important to note is that this higher complication rate did not translate into a higher graft occlusion, limb loss, or mortality rate for women. The clinical effect of this difference is probably minor when one considers the big picture.

Another important finding from these studies is more data that suggest coronary artery disease might be more difficult to diagnose and treat in women. Those women with diabetes, in particular, might have significant coronary artery disease undisclosed during routine preoperative screening, and this might affect perioperative myocardial infarction and long-term survival. More aggressive approaches, which include routine invasive testing, might be warranted in this population.

\section{Aortoiliac Occlusive Disease Aortobifemoral Bypass Grafting}

Surgical treatment of aortoiliac occlusive disease can include many different procedures. The options generally considered to be gold standards, especially for diffuse and bilateral disease, are the aortobifemoral bypass graft and aortoiliac endarterectomy with patch closure. These procedures are usually performed with synthetic material (polyester or polytetrafluoroethylene). The 5-year patency rates are expected to be approximately $90 \%$. Unfortunately, there is a lack of data that examine outcomes of these procedures according to patient sex. Schneider and colleagues ${ }^{8,9}$ published 2 reports that did not demonstrate any difference in primary and secondary graft patency, 3-year survival, and limb salvage between men and women who required aortobifemoral bypass. Valentine and associates ${ }^{10}$ reported no difference in graft patency or limb salvage between men and women in a select group of high-risk patients treated with aortobifemoral bypass graft.

\section{Percutaneous Interventions}

Treatment of inflow disease with percutaneous intervention (angioplasty, stenting, or both) has been accepted widely as first-line therapy for proximal lower-extremity occlusive disease. Five-year patency rates are usually reported to be lower than those for surgical revascularization, ${ }^{11}$ but complication severity is less, and recovery and in-hospital length of stay are shorter. Patency rates for percutaneous interventions also are affected significantly by a number of patient characteristics that include the diameter of the artery treated, the location of the artery treated (common iliac artery vs EIA), untreated comorbidities (eg, continued smoking and untreated hyperlipidemia), and the patency of the distal vasculature (especially the ipsilateral superficial femoral artery). Significant differences have been noted in outcomes between men and women. The patency of iliac artery intervention is lower in women compared with that in men. ${ }^{11,12}$ Ballard and coworkers ${ }^{11}$ compared outcomes in stent deployment and surgical reconstruction for aortoiliac occlusive disease. In both univariate and multivariate analysis, female sex was an independent variable that affected thrombosis of both interventions. Timaran and colleagues ${ }^{12}$ examined outcomes from iliac angioplasty and stenting only. They reported that female sex was an independent predictor of decreased primary patency by using multivariate analysis. EIA intervention also was an independent predictor for decreased primary patency. Women who had EIA intervention had the worst outcomes (4-fold increase in stent failure). EIA size, on the basis of the largest balloon used to perform the intervention, did not differ significantly between men and women (6.7 vs $6.5 \mathrm{~mm}$ ). Other significant predictors of stent failure were smoking and poor runoff scores. Women who received hormone replacement therapy (HRT) during the intervention and at follow-up were reported to have significantly lower patency of iliac stents than women treated similarly who were not receiving HRT (5-year patency: non-HRT users, $74 \%$; HRT users, $49 \%){ }^{13}$

\section{Conclusions}

When evaluating outcomes in patients with PAD, many variables should be considered because many different interventions are available, and many different outcome measurements need to be tabulated to make these studies reliable. All these considerations create significant obstacles to the collection of meaningful data. In terms of infrainguinal revascularization, there do not appear to be significant differences between men and women regarding the most impor- 
tant outcome measurements (limb salvage, graft patency, and mortality). In terms of both surgical and percutaneous treatment of aortoiliac occlusive disease, it is difficult to draw firm conclusions from the currently available data concerning whether a true difference exists for outcomes between women and men. This conclusion is due to the fact that findings from current studies have not been corroborated.

Future research efforts should address the following:

1. A prospective multi-institutional study has been performed to examine differing outcomes between men and women with PAD who undergo intervention. This work needs to be performed for inflow, as well as infrainguinal, disease and surgical and percutaneous interventions.

2. Further investigation on the effect of HRT in patients with PAD is warranted, especially those being treated with percutaneous techniques.

3. The physiologic basis for wound complications in women with PAD and potential approaches to improve this problem should be examined.

4. Clinical management changes to improve the longterm survival of women with diabetes and PAD should be implemented.

\section{References}

1. Roddy SP, Darling RC III, Maharaj D, Chang BB, Paty PSK, Kreienberg PB, et al. Gender-related differences in outcome: an analysis of 5880 infrainguinal arterial reconstructions. J Vasc Surg. 2003;37:399402.
2. Harris EJ Jr, Taylor LM Jr, Moneta GL, Porter JM. Outcome of infrainguinal arterial reconstruction in women. J Vasc Surg. 1993;18: 627-36.

3. Belkin M, Conte MS, Donaldson MC, Mannick JA, Whittemore AD. The impact of gender on the results of arterial bypass with in situ greater saphenous vein. Am J Surg. 1995;170:97-102.

4. Magnant JG, Cronenwett JL, Walsh DB, Schneider JR, Besso SR, Zwolak RM. Surgical treatment of infrainguinal arterial occlusive disease in women. $J$ Vasc Surg. 1993;17:67-78.

5. Mays BW, Towne JB, Fitzpatrick CM, Smart SC, Cambria RA, Seabrook GR, et al. Women have increased risk of perioperative myocardial infarction and higher long-term mortality rates after lowerextremity artery bypass grafting. J Vasc Surg. 1999;29:807-13.

6. Frangos SG, Karimi S, Kerstein MD, Harpavat M, Sumpio B, Roberts $\mathrm{AB}$, et al. Gender does not impact infrainguinal vein bypass graft outcome. Surgery. 2000;127:679-86.

7. Nam JH, Gahtan V, Roberts AB, Kerstein MD. Influence of incisional complications on infrainguinal vein bypass graft outcome. Ann Vasc Surg. 1999;13:77-83.

8. Schneider JR, Zwolak RM, Walsh DB, McDaniel MD, Cronenwett JL. Lack of diameter effect on short-term patency of size-matched Dacron aortobifemoral grafts. J Vasc Surg. 1991;13:952-63.

9. Schneider JR. Aortoiliac occlusive disease. Semin Vasc Surg. 1995;8: 277-83.

10. Valentine RJ, Hansen ME, Myers SI, Chervu A, Clagett GP. The influence of sex and aortic size on late patency after aortofemoral revascularization in young adults. J Vasc Surg. 1995;21:296-306.

11. Ballard JL, Bergan JJ, Singh P, Yonemoto H, Killeen JD. Aortoiliac stent deployment versus surgical reconstruction: Analysis of outcome and cost. J Vasc Surg. 1998;28:94-103.

12. Timaran CH, Stevens SL, Freeman MB, Goldman MH. External iliac and common iliac artery angioplasty and stenting in men and women. J Vasc Surg. 2001;34:440-6.

13. Timaran CH, Stevens SL, Grandas $\mathrm{OH}$, Freeman MB, Goldman MH. Influence of hormone replacement therapy on the outcome of iliac angioplasty and stenting. J Vasc Surg. 2001;33(suppl):S85-92. 